\title{
Clytus Gottwald:
}

\section{Zum Tode von Wolfgang Irtenkauf}

Sein Tod schneidet nicht nur $a b$, sondern fordert Innehalten und Rückblick. Dabei wird nicht ausbleiben, dass der Rückblick desjenigen, den mit dem Verstorbenen eine lange Freundschaft verband, notwendigerweise von solcher Freundschaft gefärbt ausfällt.

Ich lernte inn während des Wintersemesters $1950 / 51$ in Tübingen kennen. Im musikwissenschaftlichen Seminar hatte er über die Antiphonen eine Form des gregorianischen Chorals zu referieren. Und da ihm meine gesangliche Ausbildung zu Ohren gekommen war, bat er mich, die Beispiele zu seinem Referat vorzusingen. Bei dieser Gelegenheit erfuhr ich, dass er aus Göppingen stammte, als 17jähriger zu einer Flugabwehr-Batterie kommandiert wurde und erst 1946 das Abitur nachholen konnte. Im Abgangszeugnis fällt die „1“ in Musik aus dem Rahmen. Und so blieb nicht aus, dass er das Theologie-Studium schon nach einem Semester abbrach und zur Musikwissenschaft wechselte, um auf diese Weise der Musik nahe zu sein. In diese Zeit fällt auch seine erste Berührung mit der WLB; denn als Dissertationsthema wählte er die Untersuchung einiger Stuttgarter Choralhandschriften. Und einmal auf diese Spur gesetzt, versuchte er nach seinem Doktorexamen im Herbst 1953, die Arbeit zu einem größeren For- schungsauftrag umzugestalten. Aber die DFG (Deutsche Forschungsgemeinschaft) winkte ab. So musste er sich eine gewisse Zeit als Privatgelehrter und Musikkritiker durchschlagen. Auch dem Versuch, an der WLB als Referendar unterzukommen, blieb der Erfolg versagt. Immerhin gab man inm einen befristeten Arbeitsvertrag, und wer heute am alten Zettelkatalog nach Theologischem forscht, stößt unweigerlich auf die von seiner Hand nachgetragenen Signaturen. Dem konzertierten Bemühen von Walter Gerstenberg, Musik-Ordinarius in Tübingen, und Wilhelm Hoffmann, damals Direktor der WLB, war es zu danken, dass Irtenkauf dann doch am 1. April 1956 zur Ausbildung zum wissenschaftlichen Bibliotheksdienst übernommen wurde. Der Besuch der Münchner Bibliotheksschule hinterließ bei inm allerdings eine dauerhafte Abneigung gegen die Bayerische Staatsbibliothek.

Als Assessor in die WLB, genauer: in die Handschriftenabteilung zurückgekehrt, entfaltete er eine erstaunliche Dynamik. Wilhelm Hoffmann und er setzten etwas in Gang, was in der übrigen Bibliothekslandschaft ohne Beispiel war. Die reichen Handschriftenbestände der WLB sollten nicht nur beschaulich konserviert und gehegt, sondern durch seine fortschrittliche Ka- 
talogisierung für die Wissenschaft erschlossen werden. Und da die DFG von dieser Dynamik gleichsam mitgerissen wurde, flossen auch die Mittel, um in Stuttgart einen „brain trust“ aufzubauen, das heißt: eine Mannschaft von Wissenschaftlern verschiedener Fachrichtungen, die gleicherweise jeder für sich und doch gemeinsam an dem Projekt arbeiteten - und das noch im Altbau, beengt und unklimatisiert.

Philologen, Liturgiker, Historiker, Musikwissenschaftler und Kunsthistoriker - sie alle infizierten sich an Irtenkaufs ungebrochener Motivation. Katalogband nach Katalogband erschien und breitete immer neue Aspekte des Stuttgarter Handschriftenschatzes vor einer staunenden Wissenschaft aus.

Aber Irtenkaufs Tatendrang erschöpfte sich nicht im Bibliotheksbetrieb, sondern wollte nach außen. Unterm Schirm der Hoffmannschen Liberalität häufte er eine schier unübersehbare Menge von Artikeln, Rezensionen, Kritiken und Rundfunksendungen an, trommelte die Kollegen zur Mitarbeit an Heimatbüchern zusammen, leitete Exkursionen, führte Reisegruppen, gab die Schwäbische Heimat heraus, atmete im Schwäbischen Heimatbund als zweiter Vorsitzender, kurzum er und mit ihm die WLB waren überall präsent, wo landesgeschichtliche Themen verhandelt wurden. Ehrungen blieben nicht aus, so der Professor-Titel oder der päpstliche Silvester-Orden.
Nach seiner durch ein Augenleiden erzwungenen Pensionierung 1988 zog er, der unbeugsame Schwabe, sich ins badische Löffingen zurück, wo er bei gutem Wetter von seiner Dachluke aus den Montblanc sehen konnte. Ein schrecklicher Autounfall, den er als Beifahrer schwer verletzt überstand, verurteilte inn nicht nur zu langem Krankenlager und zu schwieriger Rehabilitation, sondern setzte eine verhängnisvolle Kette von weiteren Unfällen und Krankheiten in Gang. Operationen wechselten mit Chemotherapien, was seine Widerstandskraft schließlich so aufzehrte, dass sein Leben am 22. November erlosch, fast auf den Tag genau 50 Jahre, nachdem inn die Universität Tübingen mit magna cum laude zum Doktor promoviert hatte.

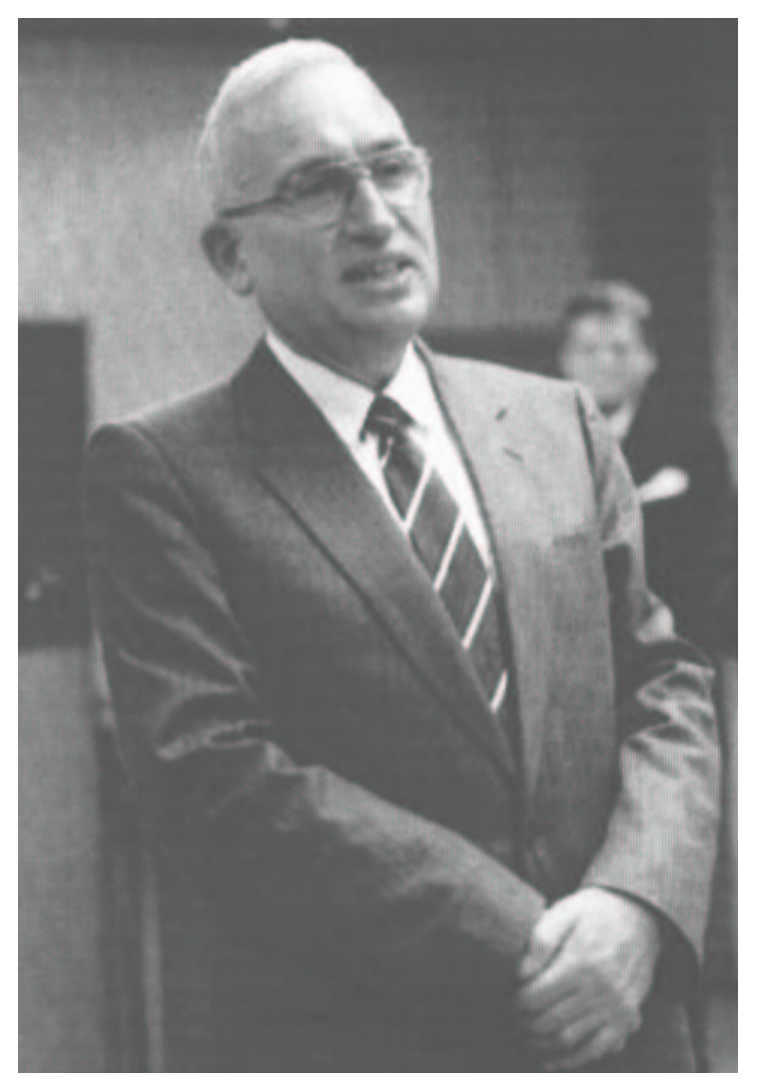

